\section{Prevalence and determinants of pre-term deliveries in the University of Ilorin Teaching Hospital, llorin, Nigeria}

\author{
Olugbenga A. Mokuolu, 'BM Suleiman,' \\ OO Adesiyun, 'A Adeniyi' \\ 'Neonatal Intensive Care Unit, \\ Department of Paediatrics, \\ University of Ilorin Teaching Hospital, \\ Ilorin, Nigeria; \\ ${ }^{2}$ Department of Paediatrics, Federal \\ Medical Centre, Katsina, Nigeria
}

\section{Abstract}

In Nigeria, over 900,000 children under the age of five years die every year. Early neonatal death is responsible for a little over $20 \%$ of these deaths. Prematurity remains a significant cause of these early neonatal deaths. In some series, it is reported to be responsible for $60-70 \%$ of these deaths. This study aimed to determine the prevalence and determinants of pre-term deliveries at the University of Ilorin Teaching Hospital, Ilorin. This was a prospective cohort study conducted over a 9-month period at the University of Ilorin Teaching Hospital. Records of deliveries and data on maternal socio-biological and antenatal variables were collected during this period in order to determine the prevalence and determinants of pre-term deliveries. Out of the 2,489 deliveries that took place over a 9 -month period, there were 293 pre-terms, giving a pre-term delivery rate of 120 per 1,000 deliveries. Of the total deliveries, 1,522 singleton deliveries that satisfied inclusion criteria were recruited; 185 of them were pre-term deliveries giving a case:control ratio of 1:7. Significant determinants of pre-term delivery identified were previous pre-term delivery $(\mathrm{P}=0.001 ; 0 \mathrm{R}=3.55$; 95\% CI=1.71-7.30), antepartum hemorrhage $(\mathrm{P}=0.000 ; 0 R=8.95 ; 95 \% \mathrm{CI}=4.06-19.78)$, premature rupture of the membranes $(\mathrm{P}=0.000$; $0 \mathrm{R}=6.48 ; 95 \% \mathrm{CI}=4.33-9.67)$, maternal urinary tract infection $\quad(\mathrm{P}=0.006 ; \quad \mathrm{OR}=5.89$; $95 \% \mathrm{CI}=1.16-27.57)$, pregnancy induced hypertension $(\mathrm{P}=0.007 ; \mathrm{OR}=3.23 ; 95 \% \mathrm{CI}=2.09-4.99)$, type of labor $(\mathrm{P}=0.000 ; 0 \mathrm{R}=6.44 ; 95 \% \mathrm{CI}=4.42$ 9.38) and booking status $(\mathrm{P}=0.000 ; \mathrm{OR}=4.67$; $95 \% \mathrm{CI}=3.33-6.56)$. The prevalence of pre-term delivery was 120 per 1,000 live births. Factors significantly associated with pre-term delivery were low socio-economic class, previous preterm delivery, antepartum hemorrhage, premature rupture of fetal membranes, urinary tract infection, pregnancy induced hypertension, induced labor, and booking elsewhere outside the teaching hospital.

\section{Introduction}

Pre-term deliveries remain a significant perinatal challenge, with pre-term babies accounting for $5-25 \%$ of all deliveries and up to $75 \%$ of all perinatal mortality in some series..$^{1-3}$ While only $0.87 \%$ of all live births occur at a gestational age less than 31 weeks, births below this gestational age are responsible for $84 \%$ of the neonatal mortalities among infants of all gestational ages in the developed world. ${ }^{4}$ In Nigeria, pre-term babies account for $40-60 \%$ of all perinatal deaths. ${ }^{5-7}$

The survival of these pre-term infants is a function of both their biological maturity and technological advancement. ${ }^{8}$ The latter has continued to improve in most developed countries, with continuing progress in neonatal intensive care, shifting the limit of viability towards younger gestational ages, with greater than $80 \%$ survival at 28 weeks gestation. ${ }^{8-11}$ Such improvements are also being seen in some developing countries, especially in Asia with survival rates of $50-60 \%$ being recorded at 26-27 weeks gestation. ${ }^{12}$ The same cannot be said for most African countries with poor health infrastructure, heavy debt burden, conflicts and endemic poverty. A previous study in Benin City recorded mortality of $92.6 \%$ in babies of less than 28 weeks gestation. ${ }^{13}$

Thus, the most rational way of reducing the impact of these deliveries on neonatal mortality is by reducing their incidence. This will be guided by a proper understanding of the risk factors associated with these deliveries.

Many factors have been associated with these deliveries. These include history of previous pre-term birth, severe maternal hypertension, spontaneous pre-term rupture of fetal membranes, maternal age over fifty years, urinary tract infection, maternal anemia, maternal illness during pregnancy, previous abortion, nulliparity and low body mass index..$^{14,15-19}$ The direct cause is, however, usually not apparent. ${ }^{15}$ Most available data come from Europe, North America and Asia, with few data from Africa. ${ }^{14 \cdot 19}$

Hence this study was conducted to estimate the prevalence of pre-term delivery and identify associated factors.

\section{Materials and Methods}

The study was conducted at the Maternity Hospital Wing of the University of Ilorin Teaching Hospital, Ilorin. This wing of the hospital provides secondary and tertiary healthcare services in neonatology, obstetrics and gynecology. It attends to both booked and unbooked emergency cases. The annual delivery rate is 2,000 to 2,500 . Deliveries are both
Correspondence: Olugbenga A. Mokuolu,

Neonatal Intensive Care Unit, Department of Paediatrics, University of Ilorin Teaching Hospital, Ilorin, Nigeria.

E-mail: mokuolu@unilorin.edu.ng

Key words: pre-term, prevalence, deliveries, Ilorin, Nigeria.

Received for publication: 24 October 2009.

Revision received: 1 February 2010.

Accepted for publication: 4 February 2010.

This work is licensed under a Creative Commons Attribution 3.0 License (by-nc 3.0).

(C) Copyright O.A. Mokuolu et al., 2010

Licensee PAGEPress, Italy

Pediatric Reports 2010; 2:e3

doi:10.4081/pr.2010.e3

vaginal (spontaneous and assisted) and operative. The neonatal intensive care unit (NICU) provides level II care to both inborn and outborn neonates. It admits between 1,000 and 1,200 patients annually.

This was a prospective cohort study conducted over nine months. All deliveries during the period of subject recruitment were recorded in order to provide a denominator for calculating the incidence of pre-term delivery and for use as controls in determining the maternal socio-biological characteristics associated with pre-term deliveries. All deliveries in the hospital during the study period were recruited, except those of mothers unsure of their LMP, those with discrepancy greater than two weeks between gestational age determined by LMP and that from Ballard assessment, and those with multiple gestations. Also excluded were those mothers whose babies had gross congenital malformations and those with post-term deliveries. Subjects were recruited consecutively once they fulfilled the inclusion criteria. Following recruitment, the subjects were grouped into pre-term and term babies. Pre-term babies were defined as those babies whose delivery occurred between gestational age 28 weeks and 37 completed weeks while term babies were those whose delivery occurred at or beyond a gestational age of 37 completed weeks but before 42 completed weeks.

A structured study proforma was completed by all subjects recruited. Data collected on maternal profile included maternal age, tribe, height, parity, antenatal status, ante-partum hemorrhage, previous pre-term delivery, previous abortion and drug intake during pregnancy. Data on weight at first antenatal care visit, packed cell volume and pregnancy induced or associated hypertension was obtained from the mother's hospital records. Socio-economic index scores were awarded to the subjects 
based on the occupations and educational attainments of their parents or caregivers using the Oyedeji socio-economic classification scheme..$^{20}$

All recruited subjects were thoroughly examined to identify any congenital malformations. Two methods of estimating gestational age were employed; the date of the mother's last menstrual period (LMP) and the Ballard score. $^{21}$ For uniformity, the gestational age derived from the Ballard score was used for analysis. Subjects were excluded when the mother was unsure of the date of her last menstrual period or when there was an irreconcilable discrepancy in the gestational age by LMP and Ballard of more than two weeks.

\section{Data analysis}

Data from the proforma were entered into a personal computer using SPSS version 15.0 for Windows software. The data was cleaned before analysis. Frequency distribution tables for variables were generated. Prevalence of pre-term delivery was determined. Potential determinants of prematurity were cross tabulated and odd ratios with their $95 \%$ confidence interval determined. $\chi^{2}$ test (with Yates correction where applicable) and Fisher's exact test were used to test for significance of the differences between categorical variables. The contribution of multiple independent variables to pre-term delivery were determined using linear regression analysis. Level of significance was put at $\mathrm{P}<0.05$.

\section{Results}

A total of 2,489 women delivered 2,589 babies over a 9-month period. Of these, 2,025 $(81.4 \%)$ of the women delivered at term, 293 (11.8\%) delivered pre-term and 171 (6.8\%) delivered post-term. Ninety-seven of the women who delivered pre-term had early preterm deliveries.

The pre-term delivery rate ( $<37$ wks) was 120 per 1,000 deliveries. Early pre-term delivery rate $(<34$ wks) was 40 per 1,000 deliveries as shown in Figure 1.

For the purpose of comparative analysis, a total of 1,522 subjects who met inclusion criteria were recruited into the study. One hundred and eighty-five of them were delivered preterm and were recruited as subjects while 1,337 were term deliveries recruited as controls. The ratio of cases to controls is 1:7. This is to reflect the proportionate contribution of pre-term birth to the total delivery.

Of the various maternal socio-demographic characteristics studied as potential determinants of pre-term delivery, maternal age of 35 years or over, social class and parity were found to be significantly associated as shown
Table 1. Maternal socio-demographic characteristics vs pre-term delivery.

\begin{tabular}{|c|c|c|c|c|}
\hline \multirow[t]{2}{*}{ Parameter } & \multicolumn{2}{|c|}{ Babies studied } & \multirow[t]{2}{*}{ Odd ratio } & \multirow[t]{2}{*}{$\mathbf{P}$} \\
\hline & Pre-term (\%) & Term (\%) & & \\
\hline \multicolumn{5}{|l|}{ Age (years) } \\
\hline$<20$ & $5(16.7)$ & $25(83.3)$ & $1.64(0.48-4.46) !$ & $0.002 *$ \\
\hline $20-34$ & $137(10.9)$ & $1125(89.1)$ & $1.91(1.29-2.82)^{\wedge}$ & S \\
\hline$\geq 35$ & $43(18.9)$ & $185(81.1)$ & & \\
\hline \multicolumn{5}{|l|}{ Social class } \\
\hline Low(III,IV,V) & 103 (15.7) & 551 (84.3) & $1.82(1.32-2.52)$ & $0.000^{*}$ \\
\hline High(I and II) & $80(9.3)$ & $780(90.7)$ & & S \\
\hline \multicolumn{5}{|l|}{ Marital status } \\
\hline Single & $5(15.2)$ & $28(84.8)$ & $1.30(0.39-3.47)$ & $0.588^{\#}$ \\
\hline Married & $180(12.1)$ & $1309(87.9)$ & & NS \\
\hline \multicolumn{5}{|l|}{ Parity } \\
\hline 0 & $5(7.7)$ & 60 (92.3) & $0.64(0.20-1.62) \sim$ & $0.001^{*}$ \\
\hline $1-4$ & 154 (11.5) & $1184(88.5)$ & $2.30(1.40-3.76)^{\circ}$ & S \\
\hline$\geq 5$ & $26(23.0)$ & $87(77.0)$ & & \\
\hline
\end{tabular}

${ }^{*} \chi^{2}$ test; ;Fisher's's exact test; S, significant; NS, not significant; 'Odd ratio for low maternal age; ^ $0 d d$ ratio for low maternal age; - Odd ratio for primiparity; ${ }^{\circ}$ Odd ratio for grandmultiparity.

Table 2. Maternal antenatal and delivery characteristics vs pre-term delivery.

\begin{tabular}{|c|c|c|c|c|}
\hline Parameter & $\begin{array}{r}\text { Babies } \\
\text { Pre-term (\%) }\end{array}$ & $\begin{array}{l}\text { tudied } \\
\text { Term (\%) }\end{array}$ & Odd ratio & $P$ \\
\hline $\begin{array}{l}\text { Packed cell volume(\%) } \\
\quad<30 \\
\geq 30\end{array}$ & $\begin{array}{l}19(8.2) \\
62(7.6)\end{array}$ & $\begin{array}{l}212(91.8) \\
756(92.4)\end{array}$ & $1.09(0.62-1.92)$ & $\begin{array}{l}0.745 \\
\text { NS }\end{array}$ \\
\hline $\begin{array}{l}\text { Previous abortion } \\
\text { Yes } \\
\text { No }\end{array}$ & $\begin{array}{r}53(13.2) \\
131(11.7)\end{array}$ & $\begin{array}{l}350(86.8) \\
987(88.3)\end{array}$ & $1.14(0.80-1.63)$ & $\begin{array}{c}0.449^{*} \\
\text { NS }\end{array}$ \\
\hline $\begin{array}{l}\text { Previous uterine curettage } \\
\text { Yes } \\
\text { No }\end{array}$ & $\begin{array}{r}31(12.9) \\
153(11.9)\end{array}$ & $\begin{array}{r}209(87.1) \\
1128(88.1)\end{array}$ & $1.09(0.71-1.68)$ & $\begin{array}{c}0.671^{*} \\
\mathrm{NS}\end{array}$ \\
\hline $\begin{array}{l}\text { Previous pre-term delivery } \\
\text { Yes } \\
\text { No }\end{array}$ & $\begin{array}{r}13(31.7) \\
171(11.6)\end{array}$ & $\begin{array}{r}28(68.3) \\
1309(88.4) \\
\end{array}$ & $3.55(1.71-7.30)$ & $\begin{array}{c}0.001^{\#} \\
\mathrm{~S}\end{array}$ \\
\hline $\begin{array}{l}\text { Febrile illness } \\
\text { Yes } \\
\text { No }\end{array}$ & $\begin{array}{r}11(22.9) \\
174(11.8)\end{array}$ & $\begin{array}{r}37(77.1) \\
1300(88.2)\end{array}$ & $2.22(1.05-4.62)$ & $\begin{array}{c}0.020^{*} \\
\mathrm{~S}\end{array}$ \\
\hline $\begin{array}{l}\text { Antepartum hemorrhage } \\
\text { Yes } \\
\text { No }\end{array}$ & $\begin{array}{r}16(53.3) \\
169(11.3)\end{array}$ & $\begin{array}{r}14(46.7) \\
1323(88.7)\end{array}$ & $8.95(4.06-19.78)$ & $\begin{array}{c}0.000^{\ddagger} \\
\mathrm{S}\end{array}$ \\
\hline
\end{tabular}

\begin{tabular}{|c|c|c|c|c|}
\hline \multicolumn{5}{|c|}{ Prolonged rupture of membrane } \\
\hline Yes & $\begin{array}{r}43(43.0) \\
142(10.0)\end{array}$ & $\begin{array}{r}57(57.0) \\
1280(90.0)\end{array}$ & $6.80(4.32-10.71)$ & $\begin{array}{c}0.000^{*} \\
\mathrm{~S}\end{array}$ \\
\hline \multicolumn{5}{|c|}{ Premature rupture of membrane } \\
\hline Yes & $56(40.0)$ & $84(60.0)$ & $6.48(4.33-9.67)$ & $0.000^{*}$ \\
\hline No & $129(9.3)$ & $1253(90.7)$ & & S \\
\hline
\end{tabular}

Urinary tract infection

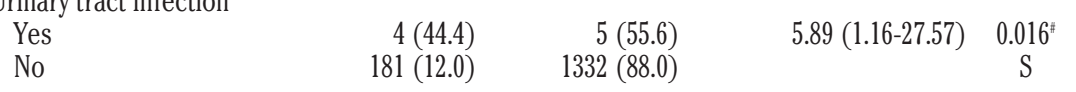

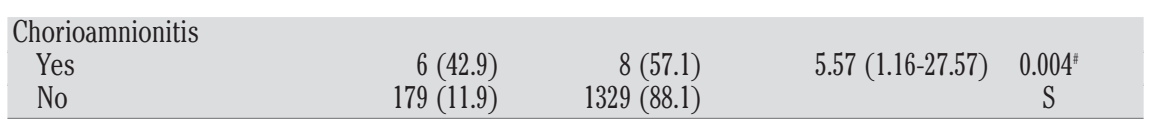

Pregnancy induced hypertension

\begin{tabular}{lrrrc} 
Yes & $37(27.8)$ & $96(72.2)$ & $5.57(1.57-18.50)$ & $0.000^{*}$ \\
No & $148(10.7)$ & $1241(89.3)$ & & $\mathrm{S}$ \\
Type of labor & & & & \\
$\quad$ Medically induced & $66(38.4)$ & $106(61.6)$ & $6.44(4.42-9.38)$ & $0.000^{*}$ \\
$\quad$ Spontaneous & $119(8.8)$ & $1231(91.2)$ & & $\mathrm{S}$ \\
\hline $\begin{array}{l}\text { Booking status } \\
\text { Elsewhere }\end{array}$ & & & \\
UITH & $84(29.4)$ & $202(70.6)$ & $4.67(3.33-6.56)$ & $0.000^{*}$ \\
\hline
\end{tabular}

${ }^{*} \chi^{2}$ test; "Fisher's exact test; $S$, significant; NS, not significant. 
in Table 1. Antenatal characteristics significant as determinants of pre-term delivery were previous pre-term delivery, febrile illness, antepartum hemorrhage, prolonged rupture of membrane and premature rupture of membrane. Others included urinary tract infection chorioamnionitis, pregnancy induced hypertension, type of labor and booking status as shown in Table 2.

A linear regression analysis was carried out to exclude the relative contribution listwise of the identified significant determinants of preterm delivery. Table 3 shows that after regression analysis, socio-economic class, previous pre-term delivery, antepartum hemorrhage, premature rupture of fetal membranes, urinary tract infection, pregnancy induced hypertension, type of labor and booking status remained significant. The model accounted for $19.6 \%$ of pre-term deliveries. Booking status was the strongest determinant of pre-term delivery.

\section{Discussion}

The study has demonstrated that pre-term delivery remains a significant problem with a hospital based prevalence rate of 120 per 1,000 deliveries. This rate is higher than would be expected from a community based study because the study center is a tertiary center which attends to referrals from other primary and secondary centers. Most normal deliveries are taken in primary and secondary centers while more complicated deliveries, like preterm labor, are referred to the teaching hospital. This reduces the denominator and thus exaggerates the pre-term delivery rate in teaching hospitals.

However, it is higher than pre-term delivery rates previously reported from Nigeria. ${ }^{13,22}$ Those reports were, however, from retrospective studies of admissions into the neonatal unit of a teaching hospital. These are not true estimates of pre-term delivery rate as many late unproblematic pre-term deliveries will not be admitted and thus, the absolute number of pre-term babies delivered will be under-reported. The absolute number of babies delivered will also be under-represented as many babies delivered without any problem will be discharged.

The prevalence rate reported in the current study was lower than those reported from Zimbabwe and Malawi. ${ }^{23,24}$ The study from Zimbabwe was also a hospital based study with a tendency for an exaggerated pre-term delivery rate while that of Malawi was a small community study in which the gestational age was allocated using second trimester ultrasound scan. The rate is, however, higher than the 5$10 \%$ reported by most European studies. ${ }^{3,25-29}$ Given the near $100 \%$ vital registration rate of most European countries, these rates will be

Table 3. Linear regression of maternal socio-demographic and antenatal variables on preterm deliveries.

\begin{tabular}{lccc} 
& Beta coefficients & T & P \\
Maternal age & -0.033 & -1.360 & 0.174 \\
Socio-economic class & -0.057 & -2.412 & 0.016 \\
\hline Parity & -0.029 & -1.188 & 0.235 \\
Previous pre-term delivery & 0.081 & 3.488 & 0.001 \\
\hline Febrile illness & 0.026 & 1.017 & 0.309 \\
Antepartum hemorrhage & 0.102 & 4.240 & 0.000 \\
\hline Prolonged rupture of membranes & 0.051 & 1.285 & 0.199 \\
Premature rupture of membranes & 0.153 & 3.931 & 0.000 \\
\hline Urinary tract infection & 0.066 & 2.746 & 0.006 \\
Chorioamnionitis & 0.013 & 0.480 & 0.632 \\
\hline Hypertension in pregnancy & 0.068 & 2.702 & 0.007 \\
Type of labor & -0.167 & -6.408 & 0.000 \\
\hline Booking status & -0.172 & -7.144 & 0.000
\end{tabular}

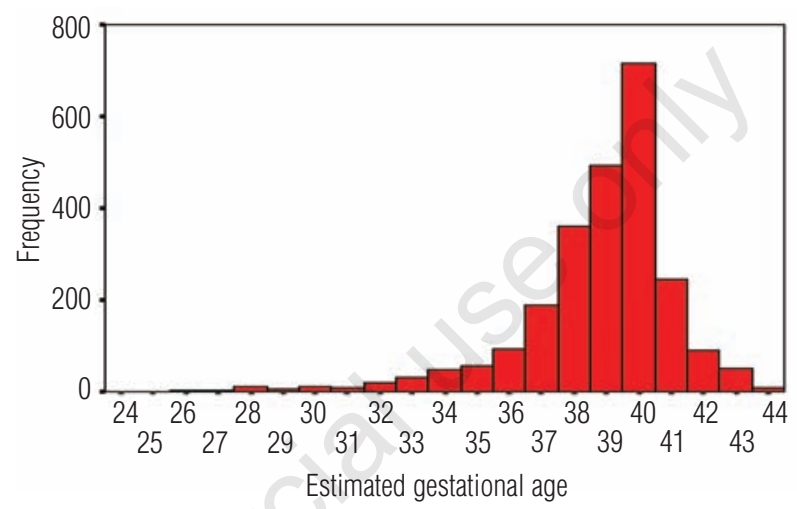

Figure 1. Distribution of all deliveries by estimated gestational age.

similar to community based pre-term delivery rate. It is, however, similar to the $12.5 \%$ reported from the United States of America. ${ }^{29}$ The American report was also based on data from vital registration.

The current study identified many maternal socio-demographic and antenatal variables, including previous pre-term delivery, antepartum hemorrhage, premature rupture of membrane, urinary tract infection, pregnancy induced hypertension, type of labor and booking status, as determinants of pre-term delivery. The model used to identify the role of multiple independent variables on pre-term delivery could only account for $19 \%$ of the pre-term deliveries. This agrees with current knowledge that most cases of pre-term delivery are unexplained. ${ }^{15}$

Previous pre-term delivery was significantly associated with pre-term delivery in this study. Previous studies had demonstrated this association. ${ }^{14,17}$ This may be due to the persistence of unidentified factors in some women precipitating pre-term delivery.

The association between antepartum hemorrhage and pre-term delivery was also significant. In the current study, most of the women with antepartum hemorrhage were medically induced to deliver. Of all cases of antepartum hemorrhage among the subjects, $56.7 \%$ were medically induced to deliver. This was higher among pre-term subjects where $62.5 \%$ were medically induced to deliver.

Premature rupture of membranes, as in other studies, ${ }^{30,31}$ was identified as a determinant of pre-term delivery in the current study. It has also been associated with subclinical chorioamninitis $^{30}$ and chlamydia vaginitis, ${ }^{31}$ both of which have also been associated with pre-term delivery. Its role is, therefore, inconclusive in that it is not clear whether premature rupture of membrane is the primary event that leads to pre-term delivery or whether there is an underlying problem like subclinical chorioamninitis that leads to both premature rupture of membrane and preterm delivery. Subclinical chorioamnionitis can initiate labor by stimulating the production of interleukin- $1 .^{32}$ Interleukin-1 is known to indirectly serve as a signal for the initiation of labor in cases of intrauterine or systemic infection by inducing prostaglandin production by intrauterine tissues. ${ }^{33}$

Urinary tract infection was significantly associated with pre-term delivery. Urinary tract infection is favored by the morphological and functional changes that take place in pregnancy. Relative stasis of urine due to pregnancy-induced changes in the urinary tract is one such factor predisposing to urinary tract infection. Infection stimulates the production of cytokines among which is interleukin-1, a known stimulant of labor through the produc- 
tion of prostaglandins from uterine tissue..$^{32,33}$ Previous studies have shown that urinary tract infection increases the risk of pre-term labour. $^{15}$

Pregnancy induced hypertension has been associated with pre-term delivery in previous studies. ${ }^{17,19}$ This study also found an association between pregnancy induced hypertension and pre-term delivery. Reduced placental perfusion may be the mechanism that induces pre-term labor. Many patients with pregnancy induced hypertension, however, are medically induced to deliver either vaginally or operatively. In this study, $46.6 \%$ of all subjects with pregnancy induced hypertension were medically induced to deliver. This percentage increased to $75.7 \%$ among pre-term subjects with pregnancy induced hypertension. These associations were significant with a $P$ value of less than 0.05 . Thus, the role of pregnancy induced hypertension in pre-term delivery in this study has more to do with medical intervention than with a direct causal relationship.

Studies have shown that many pre-term deliveries are due to medical intervention either for maternal or fetal reasons $s^{26,3435}$ and this is confirmed in this study. Those maternal reasons identified to be predominant causes of medical intervention in this study were pregnancy induced hypertension and antepartum hemorrhage. Booking status of subjects was also identified as the strongest determinant of pre-term delivery. A problem, with a potential to result in pre-term delivery, in a woman with a booked and well supervised pregnancy is likely to be detected early. Such a woman, with appropriate management, may have her pregnancy managed to term. A similar problem in a woman with a pregnancy that is either not booked or poorly supervised, will likely be identified late. This increases the chances of spontaneous or medically induced premature delivery. In this study, there was no significant difference between spontaneous and medically induced delivery among all recruited pre-term subjects based on booking status $(\mathrm{P}=0.531)$.

\section{References}

1. Demissie K, Rhoads GG, Ananth CV, et al. Trends in preterm birth and neonatal mortality among blacks and white in the United States of America from 1989 to 1997. Am J Epidemiol 2001;154: 307-15.

2. Ezechukwu CC, Ugochukwu EF, Egbuonu I, Chukwuka J0. Risk factors for neonatal mortality in a regional tertiary hospital in Nigeria. Nig J Clin Pract 2004;7:50-2.

3. Steer P. The epidemiology of preterm labour. Br J Obstet Gynaecol 2005;112:1-3.

4. Usher R. Extreme prematurity. In: Avery GB(Ed). Neonatology pathophysiology and management of the Newborn. Philadelphia: JB Lippincott(Publ) 1987; 264.

5. Chike-Obi U. Preterm delivery in Ilorin; multiple and teenage pregnancies major aetiologic factors. West Afr J Med 1993;12: 228-30.

6. Njokanma OF, Olanrewaju DM. A study of neonatal deaths at the Ogun State University Teaching Hospital, Sagamu, Nigeria. J Trop Paediatr 1995;98:155-60.

7. Njokanma OF, Sule Odu OA, Akesode FA. Perinatal mortality at the Ogun State University Teaching Hospital, Sagamu, Nigeria. J Trop Paediatr 1994;40:78-81.

8. Breborowicz GH. Limit of fetal viability and its enhancement. Early Pregnancy 2001;5: 49-50.

9. Lorenz JM. The outcome of extreme prematurity. Semin Perinatol 2001;25:348-59.

10. Allen MC, Donohue PK, Dusman AE. The limit of viability-neonatal outcome of infants born at 22 to 25 weeks gestation. N Engl J Med 1993;329:1597-601.

11. Dunn PM, Stirrat GM. Capable of being born alive? Lancet 1984;1:553-5.

12. Sehgal A, Telang S, Passah SM, Jyothi MC. Maternal and neonatal profile and immediate outcome in extremely low birthweight babies in Delhi. Trop Doct 2004; 34:165-8.

13. Ibhanesebhor SE, Afadapa MA. Epidemiology of preterm delivery in Benin City. Nig $\mathrm{J}$ Paediatr 1996:23:27-32.

14. Mokuolu A0, Abdul IF, Adesiyun 0 . Maternal factors associated with early spontaneous singleton preterm delivery in Nigeria. Trop J Obstet Gynaecol 2002; 19:32-5.

15. Harlow BL, Frigoletto FD, Cramer DW, et al. Determinants of preterm delivery in low risk pregnancies. The RADIUS study group. J Clin Epidemiol 1996;49;441-8.

16. Olsen P, Laara E, Rantakallio P, et al. Epidemiology of preterm delivery in two birth cohorts with an interval of twenty years. Am J Epidemiol 1995;142:1184-93.

17. Wildschut HI, Petus TJ. Determinants of preterm birth in Curacao, Netherlands Antilles. Int J Gynaecol Obstet 1991;36:23-7.

18. Meda N, Soula G, Dabis F, et al. Risk factors in prematurity and intra uterine growth retardation in Burkina Faso. Rev Epidemiol Sante Publique 1995;43:215-24.

19. Sehgal A, Telang S, Passah SM, Jyothi MC Maternal and neonatal profile and immediate outcome in ELBW babies. Indian Pediatr. 2003; 10:991-5.

20. Araoye MO. Subject selection and sample size determination. In: Araoye M0, ed. Research methodology with statistics for health and social sciences. Nathadex Publishers 2003:115-20.

21. Ballard JL, Novak KK, Driver M. A simplified score for assessment of foetal maturity of newborn infants. J Pediatr 1979;95:769.
22. Omene JA, Okolo AA, Imoedehme D, Omu $\mathrm{AE}$. Trend in perinatal mortality rates at the University of Benin Teaching Hospital, Nigeria. East Afr Med J 1984;61:461-9.

23. Feresu SA, Harlow SD, Welch K, Gillespie BW. Incidence of and sociodemographic risk factors for stillbirth, preterm birth and low birthweight among Zimbabwean women. Paediatr Perinat Epidemiol 2004; 18:154-63.

24. Van den Broek N, Ntonya C, Kayira E, et al. Preterm birth in rural Malawi: high incidence in ultrasound-dated population. Human Reprod 2005;20:3235-7.

25. Bibby E, Stewart A. The epidemiology of preterm birth. Neuro Endocrinol Lett 2004; 25:43-7.

26. Morken NH, Kallen K, Hagberg $\mathrm{H}$, Jacobsson B. Preterm birth in Sweden 1973-2001: rate, subgroups, and effect of changing patterns in multiple births, maternal age, and smoking. Acta Obstet Gynecol Scand 2005;84:558-65.

27. Wisborg K, Henriksen TB, Hedegaard M, Secher NJ. Smoking during pregnancy and preterm birth. Br J Obstet Gynaecol 1996; 103:800-5.

28. Grjibovski AM, Bygren LO, Yngve A, Sjostrom M. Large social disparities in spontaneous preterm birth rates in transitional Russia. Public Health 2005;119:7786.

29. Donna LH, Mathews TJ, Menacker F, et al. Annual Summary of Vital Statistics: 2004. Pediatrics 2006;117:168-83.

30. Romero R, Sirtori M, Oyarzun E, et al. Infection and labour, V: Prevalence, microbiology and significance of intraamniotic infection in women with preterm labour and intact membrane. Am $\mathrm{J}$ Obstet Gynaecol 1989;161:817-24.

31. Martin DH, Koutsky L, Eschenbach DA, et al. Prematurity and perinatal mortality in pregnancy complicated by maternal Chlamydia trachomatis infection. JAMA 1982;247:1585-8.

32. Rebecca H Buckley. The T-, B-, and NK-Cell Systems. In: Behrman RE, Kliegman RM, Jenson HB (Eds). Nelsons Textbook of Paediatrics. 17th edition. WB Saunders Co (Publ) 2004:683-700.

33. Romero R, Mazor M, Wu YK, et al. Infection in the pathogenesis of preterm labour. Semin Perinatol 1988;12:262-79.

34. Philip Steer, Caroline Flint. ABC of labour care: Preterm labour and premature rupture of membranes. Br Med J 1999;318: 1059-62.

35. Ananth CV, Vintzileos AM. Maternal-fetal conditions necessitating a medical intervention resulting in preterm birth. Am J Obstet Gynaecol 2006;195:1557-63. 